\title{
THE IMPACT OF DRIVING CONDITIONS ON LIGHT-DUTY VEHICLE EMISSIONS IN REAL-WORLD DRIVING
}

\author{
Dong GUO, Jinbao ZHAO, Yi XU, Feng SUN, Kai LI, Juan WANG, Yuhang SUN \\ School of Transportation and Vehicle Engineering, Shandong University of Technology, China
}

Received 16 July 2017; revised 15 November 2017, 17 January 2018, 6 July 2018; accepted 13 September 2018; first published online 19 March 2020

\begin{abstract}
To accurately estimate the effect of driving conditions on vehicle emissions, an on-road light-duty vehicle emission platform was established based on OEM- $2100^{\mathrm{TM}}$, and each second data of mass emission rate corresponding to the driving conditions were obtained through an on-road test. The mass emission rate was closely related to the velocity and acceleration in real-world driving. This study shows that a high velocity and acceleration led to high real-world emissions. The vehicle emissions were the minimum when the velocity ranged from 30 to $50 \mathrm{~km} / \mathrm{h}$ and the acceleration was less than $0.5 \mathrm{~m} / \mathrm{s}^{2}$. Microscopic emission models were established based the on-road test, and single regression models were constructed based on velocity and acceleration separately. Binary regression and neural network models were established based on the joint distribution of velocity and acceleration. Comparative analysis of the accuracy of prediction and evaluation under different emission models, total error, second-based error, related coefficient, and sum of squared error were considered as evaluation indexes to validate different models. The results show that the three established emission models can be used to make relatively accurate prediction of vehicle emission on actual roads. The velocity regression model can be easily combined with traffic simulation models because of its simple parameters. However, the application of neural network model is limited by a complex coefficient matrix.
\end{abstract}

Keywords: on-road emission test, driving conditions, light-duty vehicle, velocity, acceleration, mass emission rate.

\section{Introduction}

Vehicle emission is one of the major factors affecting urban atmosphere. Vehicle emissions are affected by not only inherent conditions such as the engine technology and emission control technologies, but also the actual driving conditions on the road. It is important to quantitatively measure emissions under different driving conditions, providing driving strategies for drivers and optimizing traffic control strategies to reduce emissions (Cheng et al. 2009; Zi et al. 2006; Guo et al. 2012).

Vehicle emission under different working conditions have been extensively studied, such as COPERT (https:// www.emisia.com/utilities/copert) and EMFAC (https:// www.arb.ca.gov/emfac) models. The COPERT model (Kouridis et al. 2000) was developed by the European Environmental Bureau (EEB) using the basic emission correction factor and external parameters and emission factor in computer emulator considering the effect of the running state of vehicle emissions, deterioration, environmental conditions, and fuel oil as the external influencing factors. The disadvantage of this model is that it focused on average speed and vehicle type as the main factors influencing emission. The age of the vehicle had less influence. Vehicle emissions and fuel type mainly affect the accuracy of calculation results (Boulter et al. 2007). The EMFAC model was developed by California Air Resources Bureau (CARB). Each type of vehicle was sampled every year, and the model was updated. Bai et al. (2009) applied the EMFAC model to simulate $\mathrm{CO}_{2}$ emission from vehicles in California (US). By comparing the calculation results with the MOtor Vehicle Emission Simulator (MOVES) model (https://www.epa.gov/moves), the simulation results show that the $\mathrm{CO}_{2}$ emission had slight difference in 2002, but the $\mathrm{CO}_{2}$ emission obtained from the MOVES model was almost $40 \%$ higher than the EMFAC model in 2030. In addition, Hong Kong applied the modified EMFAC model to its traffic, and the emission was calculated based on dynamic traffic data. This better reflects the inventory and traffic control ability of vehicle emissions in Hongkong.

${ }^{\star}$ Corresponding author. E-mail: sunfeng@sdut.edu.cn 
At present, the new developed emission models such as MOVES, International Vehicle Emissions (IVE, $h t t p: / /$ www.issrc.org/ive) are microscopic and use on-road test data. Compared to macroscopic emission models based on average velocity, microscopic models can better reflect the effect of operating conditions on vehicle emission and thus provide more effective emission control strategies (Guo et al. 2016, 2017). In the MOVES model (EPA 2007), using the Vehicle Specific Power (VSP) calculation method for emission, the model can depict vehicle emissions in different modes of operation. However, the actual operation modes are relatively less in the traffic network, and the results lead to poor stability. IVE model was developed to estimate exhaust emissions in developing countries. This model is based on the calculation method for zero emission factor and deterioration rate and introduces driving behaviour parameters to correct the emission factors. The main advantage of this method is that the data can reflect the local characteristics of developing countries, and the parameters of the fit are higher. However, the classification parameters of engine stress model calculation are more complex, and it is also difficult to obtain the actual traffic conditions. Therefore, it is not suitable for the dynamic analysis of traffic emissions (Davis et al. 2005).

In terms of emission inventory and analysis of influencing factors, Liu et al. (2011) studied vehicle emissions in Nanjing city based on the IVE model using a vehicle emission analyser and Global Positioning System (GPS), obtained the data of actual driving conditions, and calculated the $\mathrm{NO}_{\mathrm{x}}$ correction factor in the emission model. Taking the city of Hangzhou as an example, Li et al. (2012) established the vehicle $\mathrm{NO}_{\mathrm{x}}$ emission inventory of Hangzhou through experiments and simulation and predicted the $\mathrm{NO}_{\mathrm{x}}$ emission of vehicles during the "12th five-year" period. Qiu et al. (2015) simulated the effects of different engine speeds, torques, engine temperatures, and intake pressures on HC emissions. Li and Zhang (2014) introduced a speed calculation method based on carbon emissions to solve the path planning problem. The above studies were aimed at the emission of a single vehicle or influencing factors; the characteristics of vehicle emissions have not been studied in detail.

In terms of emission data acquisition, Iqbal et al. (2016) investigated vehicle mileage and traffic volume data to evaluate vehicle emission characteristics in selected representative roads. The data were obtained in a short time span, and the traffic flow and vehicle emission characteristics were ignored. The obtained static data cannot be updated dynamically, and real-time calculations cannot be performed. Tang et al. (2018) used the IVE model to calculate the local vehicle emissions in Hangzhou city (urban, suburban, and rural areas) as well as for four different road types and analysed the vehicle emission characteristics. Gao et al. (2012) established a quantitative model of traffic emissions from traffic characteristics with microscopic changes and built a dynamic simulation platform for traffic emission in West Sanhuan trunk road (ArcGIS). The emission characteristics were analysed by a macro emission model or simulation. The accuracy of calculation or simulation is insufficient than the actual data, less applicable for the microanalysis of a single car. However, microscopic studies on vehicle emissions at different velocities and accelerations are still scarce. Moreover, when using a macroscopic emission model to measure vehicle emission quantitatively, its accuracy cannot satisfy the requirements. For example, different accelerations would cause huge differences in vehicle emissions under driving conditions (Li et al. 2009; Demir et al. 2011).

In this study, in order to make a detailed microscopic study on vehicle emissions of different velocities and accelerations, and put forward an effective emission control strategy, an emission test platform was established based on light-duty vehicles, and experiments were carried out at the peak and common periods in selected city ring roads. The vehicle emission data under the corresponding velocity and acceleration were obtained. Then, the difference in light-duty vehicle emissions including $\mathrm{NO}_{\mathrm{x}}, \mathrm{HC}$, and $\mathrm{CO}$ under different velocities, accelerations, and joint distribution of velocity and acceleration were analysed, providing pertinent driving suggestions. To accurately estimate vehicle emissions with driving conditions, three microscopic emission models were established: single regression, binary regression, and neural network model. The accuracy of prediction and application of these models were compared.

\section{Data source}

\subsection{On-road emission test platform}

In the study, an emission measuring instrument OEM$2100^{\mathrm{TM}}$ manufactured by CATI (US) was used. It is composed of a five-gas analyser, an engine state detector, and a computer. The five-gas analyser was used to test the volume percentage of $\mathrm{CO}, \mathrm{HC}, \mathrm{NO}_{\mathrm{x}}, \mathrm{CO}_{2}$ and $\mathrm{O}_{2}$. The engine state detector measures the per second engine speed, engine temperature, and intake pressure by connecting an On-Board Diagnostics (OBD) with the engine. This instrument first calculates the emission volume flow using the measured engine parameter data and then calculates the instantaneous mass emission rate by combining exhaust concentration data with exhaust flow data. Mass emission rate is calculated as follows:

$$
\begin{aligned}
& \text { exhaust concentration }[\mathrm{g} / \mathrm{L}] \text {. Exhaust flow }[\mathrm{L} / \mathrm{s}]= \\
& \text { mass emission rate }[\mathrm{g} / \mathrm{s}] \text {. }
\end{aligned}
$$

As shown in Figure 1, the system to measure driving conditions consists of a GPS, a laptop, and an interface program to monitor the on-road position, velocity, and acceleration of a light-duty vehicle.

\subsection{Test projects}

According to the classification of vehicles mentioned in the Measuring Method of Urban Vehicle Emission Pollution set by the Scottish Environment Protection Agency (SEPA) in 2005, light-duty vehicles have a weight of less 
than $3.5 \mathrm{t}$. According to this standard, five types of lightduty vehicles were selected for this test as shown in Table 1 .

In vehicle emission studies, average velocity is an important factor to analyse vehicle emission. Therefore, the influencing factors, average velocity, traffic congestion, and changes in traffic flow in morning and evening should be considered when selecting testing roads. As shown in Figure 2, the Red Flag Street and Yan'an Street were selected as the testing roads that have a large traffic flow, and traffic jam often occurs in the peak period. These easily cause congestion and affect the travel of traffic participants.

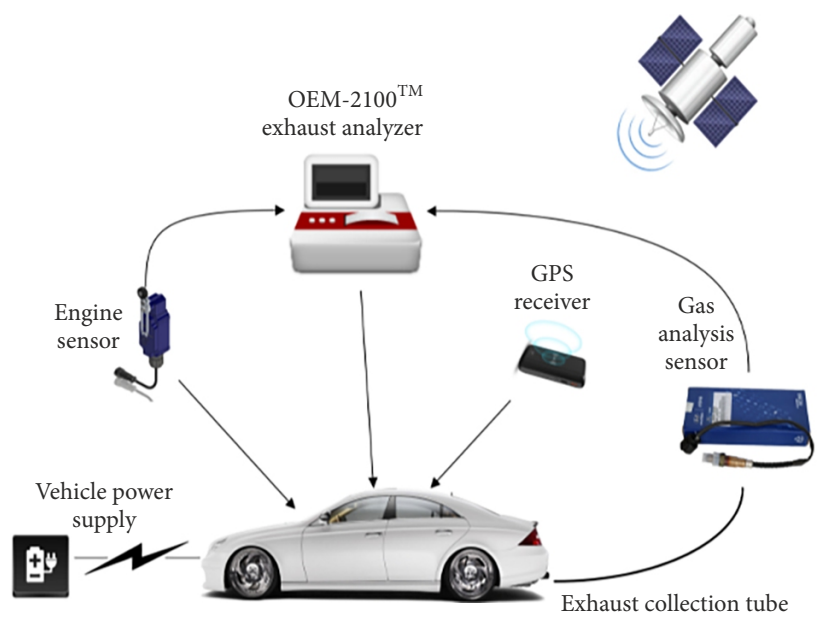

Figure 1. On-board emission test platform light-duty vehicles

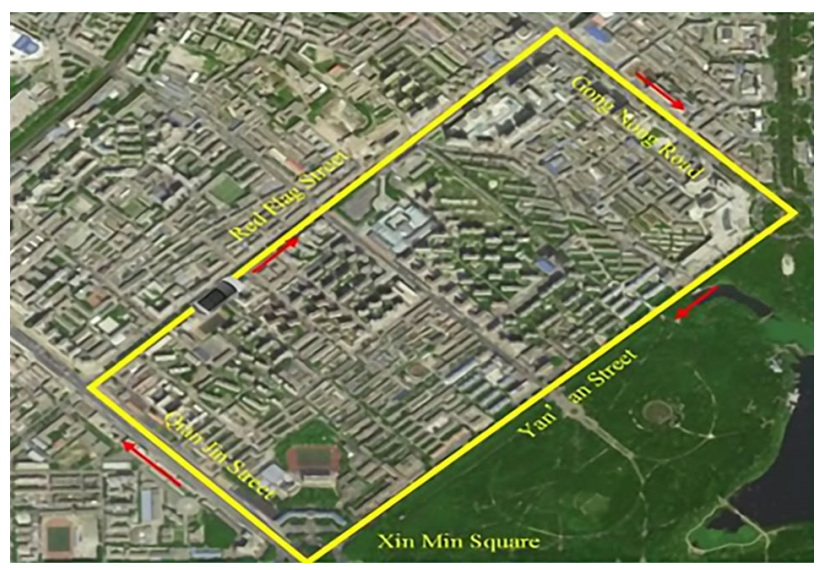

Figure 2. Regional GPS testing road map

Table 1. Five types of light-duty vehicles tested

\begin{tabular}{|l|c|c|c|}
\hline Vehicle category & $\begin{array}{c}\text { Production } \\
\text { date } \\
\text { [year] }\end{array}$ & $\begin{array}{c}\text { Travelled } \\
\text { distance } \\
{[\mathrm{km}]}\end{array}$ & $\begin{array}{c}\text { Engine } \\
\text { displacement } \\
{[\mathrm{L}]}\end{array}$ \\
\hline VW Jetta Gix & 2001 & 52000 & 1.6 \\
\hline HongQi CA7201 & 2004 & 45000 & 2.0 \\
\hline VW Jetta Gix & 2002 & 33000 & 1.6 \\
\hline VW Santana Vista & 2007 & 15000 & 1.8 \\
\hline BenTeng B50 & 2008 & 12000 & 1.6 \\
\hline
\end{tabular}

The test was conducted in three periods: the morning peak period, evening peak period, and common period. The low experienced drivers' characteristics are usually aggressive, unsteady, conservative and novice (less than 3 years of driving experience), however, the experienced drivers are often smooth going and speeding. Zheng et al. (2017) analysed the influence of different characteristics drivers (experienced and low experienced) on the emission of their car. According to their research, the low experienced drivers increased emissions of $\mathrm{CO}_{2}$ by $80.5 \%$ over experienced drivers per star-stop, and the emissions of $\mathrm{NO}_{\mathrm{x}}$ increased from $0.0033 \mathrm{~g}$ (experienced) to $0.087 \mathrm{~g}$ (low experienced) per start-stop. Furthermore, the low experienced drivers have more frequent start-stop, which further leads to an increase in emissions. In our test, two drivers with more than 10 years of driving experience were selected, thereby eliminating the influence of driver factors. To ensure that the test data are representative, five types of vehicles were tested more than 150 test runs in the three city ring roads during three periods. OEM-2100 automatically organized the test data, finally providing the vehicle mass emission rate of $\mathrm{NO}_{\mathrm{x}}, \mathrm{HC}$, and $\mathrm{CO}$ and the corresponding velocity, acceleration, and other driving conditions. The data were processed including the loss of data, and removing the wrong data. Thus, an emission database containing vehicle emission data and the corresponding driving condition data was obtained, as shown in Table 2.

\section{Analysis}

During the driving, changes in the velocity and acceleration of vehicle would affect the engine performance such as the engine temperature and combustion temperature in the cylinder, thus affecting the three mass emission rates.

\subsection{Effect of velocity}

As vehicle emissions are closely related with the velocity, the effect of velocity on emission was analysed in detail. First, the test data were acquired at an interval of $1 \mathrm{~km} / \mathrm{h}$ velocity, and the average mass emission rates were calculated at 51 velocity points at the interval of $1 \mathrm{~km} / \mathrm{h}$ between $0 \ldots 50 \mathrm{~km} / \mathrm{h}$. Figure 3 shows the changes in the three mass emission rates with velocity.

As shown in Figure 3, the $\mathrm{NO}_{\mathrm{x}}$ mass emission rate gradually increases with velocity. This is because when a car is driven at a high velocity, its engine throttle opens significantly, and its cylinder combustion temperature increases sharply. Therefore, the $\mathrm{NO}_{\mathrm{x}}$ emissions increase accordingly. In contrast, the $\mathrm{HC}$ and $\mathrm{CO}$ mass emission rates increase with velocity until it reaches a certain value. This turning point results from the fact that combustion is improved by the turbulence mixing, eddy diffusion, and exhaust turbulence of gas mixture, thus promoting the secondary oxidation of a quenching layer, which in turn promotes oxidation reaction inside the exhaust pipe. 
Table 2. Vehicle emission data and the corresponding driving conditions

\begin{tabular}{|c|c|c|c|c|c|c|}
\hline \multirow{2}{*}{ Time } & \multirow{2}{*}{$\begin{array}{c}\text { Engine speed } \\
n[\mathrm{rpm}]\end{array}$} & \multicolumn{3}{|c|}{ Emission rate } & \multirow{2}{*}{$\begin{array}{c}\text { Vehicle velocity } \\
v[\mathrm{~km} / \mathrm{h}]\end{array}$} & $\begin{array}{c}\text { Vehicle acceleration } \\
a\left[\mathrm{~m} / \mathrm{s}^{2}\right]\end{array}$ \\
\cline { 3 - 6 } & 1704 & 0.14906 & 0.03419 & 3.48397 & 20 & 0.583333 \\
\hline $9: 00: 01$ & 1403 & 0.12864 & 0.02867 & 2.6661 & 22.1 & 0.138889 \\
\hline 9:00:02 & 1308 & 0.10212 & 0.0203 & 2.3969 & 22.6 & 0.722222 \\
\hline $9: 00: 03$ & 1438 & 0.13389 & 0.02429 & 2.8943 & 25.2 & 0.722222 \\
\hline $9: 00: 04$ & 1715 & 0.16481 & 0.02781 & 1.4981 & 27.8 & 0.833333 \\
\hline $9: 00: 05$ & 1661 & 0.17481 & 0.03284 & 1.24072 & 30.8 & 0.250000 \\
\hline $9: 00: 06$ & 1336 & 0.14427 & 0.02613 & 1.2439 & 31.7 & 0.277778 \\
\hline $9: 00: 07$ & 1362 & 0.15294 & 0.02679 & 1.17642 & 32.7 & 0.416667 \\
\hline $9: 00: 08$ & 1433 & 0.15683 & 0.0274 & 1.16361 & 34.2 & 0.472222 \\
\hline $9: 00: 09$ & 1498 & 0.15382 & 0.02646 & 1.17006 & 35.9 & 0.500000 \\
\hline $9: 00: 10$ & & & & $\mathrm{HC}[\mathrm{mg} / \mathrm{s}]$ & \\
\hline
\end{tabular}

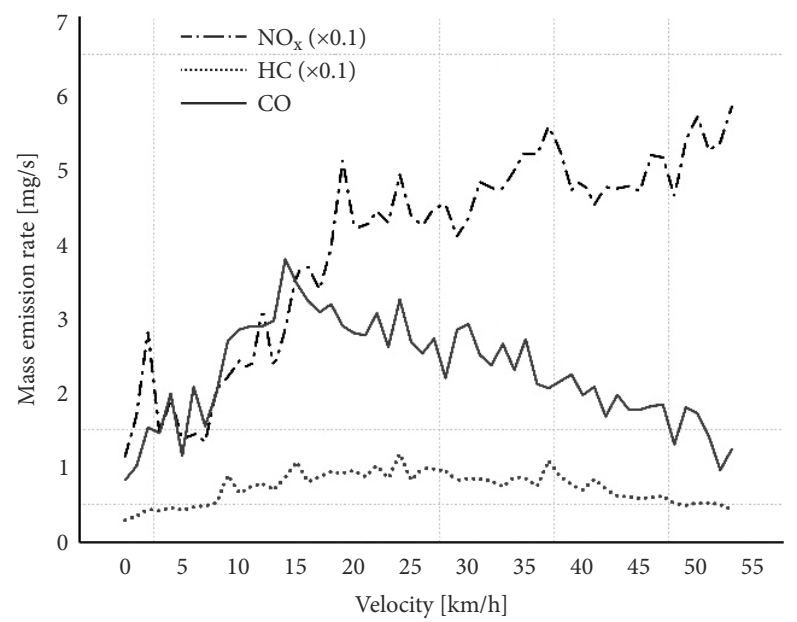

Figure 3. Changes in $\mathrm{NO}_{\mathrm{x}}, \mathrm{HC}$, and $\mathrm{CO}$ mass emission rates with velocity

Table 3. Mass emission rates of $\mathrm{NO}_{\mathrm{x}}, \mathrm{HC}$, and $\mathrm{CO}$ under different velocity ranges

\begin{tabular}{|c|c|c|c|}
\hline \multirow{2}{*}{$\begin{array}{c}\text { Vehicle velocity } \\
v[\mathrm{~km} / \mathrm{h}]\end{array}$} & \multicolumn{3}{|c|}{ Emission rate } \\
\cline { 2 - 4 } & $\mathrm{NO}_{\mathrm{x}}[\mathrm{mg} / \mathrm{s}]$ & $\mathrm{HC}[\mathrm{mg} / \mathrm{s}]$ & $\mathrm{CO}[\mathrm{mg} / \mathrm{s}]$ \\
\hline $0 \ldots 10$ & 0.17 & 0.05 & 1.62 \\
\hline $10 \ldots 20$ & 0.33 & 0.08 & 3.11 \\
\hline $20 \ldots 30$ & 0.44 & 0.09 & 2.74 \\
\hline $30 \ldots 40$ & 0.49 & 0.08 & 2.39 \\
\hline $40 \ldots 50$ & 0.48 & 0.06 & 1.79 \\
\hline$>50$ & 0.55 & 0.05 & 1.33 \\
\hline
\end{tabular}

Based on the test data, the average mass emission rates of $\mathrm{NO}_{\mathrm{x}}, \mathrm{HC}$, and $\mathrm{CO}$ under six different velocity ranges were calculated. The results are shown in Table 3.

\subsection{Effect of acceleration}

To evaluate the effect of acceleration on mass emission rates of $\mathrm{NO}_{\mathrm{x}}, \mathrm{HC}$, and $\mathrm{CO}$, six ranges of acceleration were studied: $a \leq-2 \mathrm{~m} / \mathrm{s}^{2},-2<a \leq-1 \mathrm{~m} / \mathrm{s}^{2},-1<a \leq 0 \mathrm{~m} / \mathrm{s}^{2}$, $0<a \leq 1 \mathrm{~m} / \mathrm{s}^{2}, 1<a \leq 2 \mathrm{~m} / \mathrm{s}^{2}$ and $a>2 \mathrm{~m} / \mathrm{s}^{2}$. The average

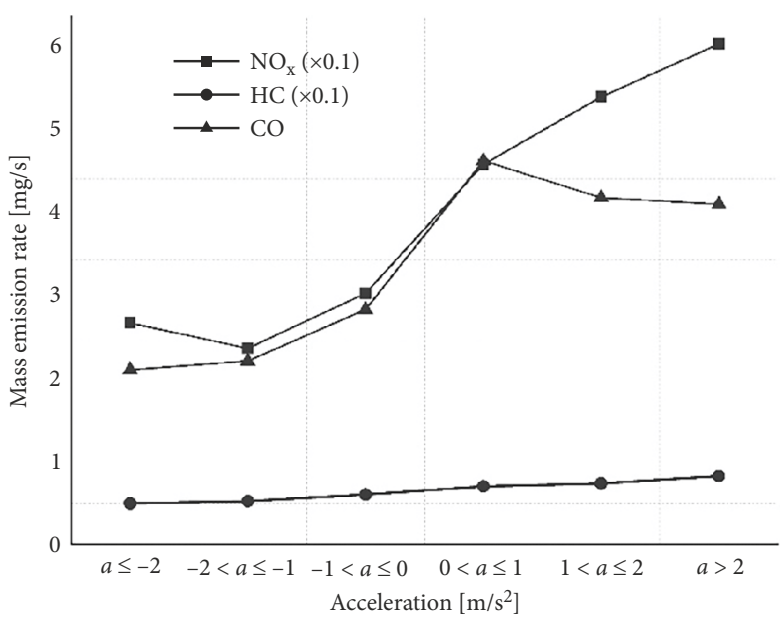

Figure 4. Changes in $\mathrm{NO}_{\mathrm{x}}, \mathrm{HC}$, and $\mathrm{CO}$ mass emission rates with acceleration

mass emission rates of three emissions in each range were calculated and drawn as a curve in Figure 4.

Figure 4 shows that with the increase in acceleration, the mass emission rate of $\mathrm{NO}_{\mathrm{x}}$ first decreased and then increased when the acceleration is above $-2 \mathrm{~m} / \mathrm{s}^{2}$. However, the mass emission rate of $\mathrm{HC}$ linearly increased with acceleration. In contrast to $\mathrm{NO}_{\mathrm{x}}$, the mass emission rate of $\mathrm{CO}$ first increased and then slightly decreased when the acceleration was more than $1 \mathrm{~m} / \mathrm{s}^{2}$.

With the increase in acceleration, the homogeneity of the mixture in cylinder was destroyed. The combustion state of mixture compared to the steady state was also destroyed. Therefore, when a car accelerates, vehicle emissions change drastically, throttle opens significantly, and combustion temperature in the cylinder increases sharply. As a result, the $\mathrm{NO}_{\mathrm{x}}$ emission increases accordingly. On the other hand, with the increase in the amount of injected fuel during the acceleration, the consistency of gas mixture increases, thus increasing the consistency of $\mathrm{CO}$ and $\mathrm{HC}$ in the emission. Moreover, the secondary formation of oil droplets over the fuel surface also thickens the gas mixture, leading to denser concentrations of CO. 


\subsection{Effect of joint distribution of velocity and acceleration}

Velocity and acceleration jointly affect the generation of three pollutants of a motor vehicle on road. In the following analysis, the variation in the mass emission rates of three pollutants is presented under the joint distribution of velocity and acceleration.

Figure 5 shows that the mass emission rate of $\mathrm{NO}_{\mathrm{x}}$ had a consistent increasing trend with velocity in different acceleration ranges. Under a fixed velocity, a larger acceleration causes a significantly higher mass emission rate of $\mathrm{NO}_{\mathrm{x}}$.

When the velocity is higher than $10 \mathrm{~km} / \mathrm{h}$ and the acceleration is higher than $1.5 \mathrm{~m} / \mathrm{s}^{2}$, the mass emission rate of $\mathrm{NO}_{\mathrm{x}}$ is obviously higher than that in other sections. This is because when a car accelerates at a high velocity, its throttle opens significantly, and the combustion tem-

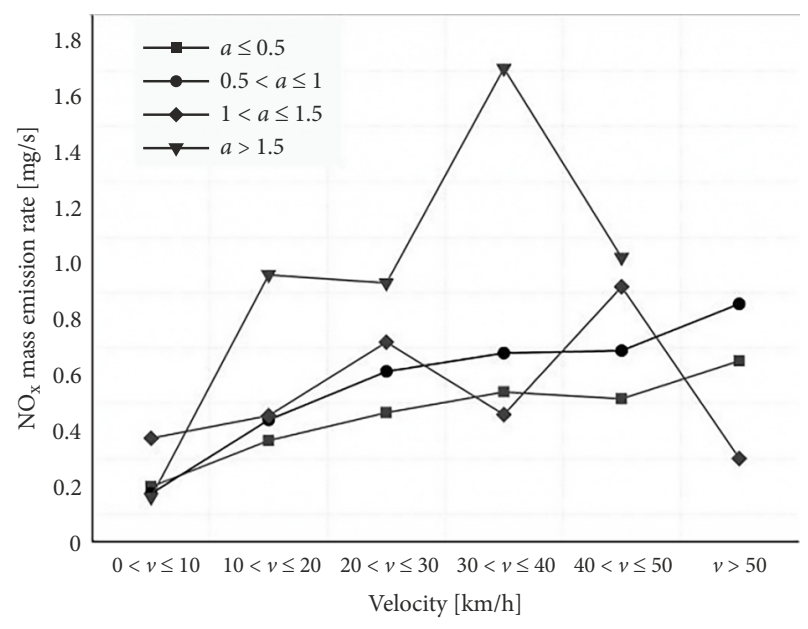

Figure 5. Effect of both velocity and acceleration on the mass emission rate of $\mathrm{NO}_{\mathrm{x}}$

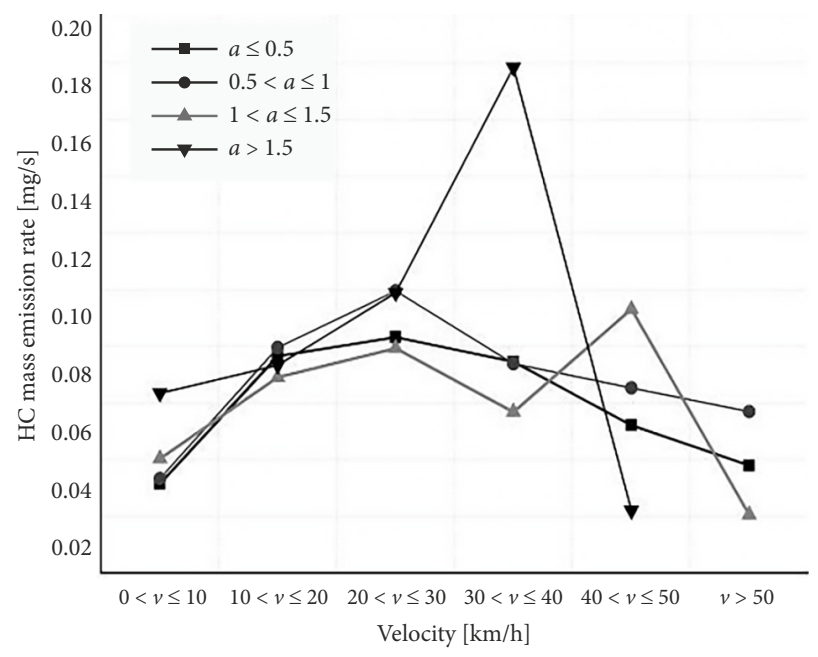

Figure 6. Effect of both velocity and acceleration on the mass emission rate of $\mathrm{HC}$ perature in cylinder sharply increases, thus increasing the emission of $\mathrm{NO}_{\mathrm{x}}$. When the velocity is low, the mass emission rate of $\mathrm{NO}_{\mathrm{x}}$ is considerably lower than that at a high velocity. Therefore, high velocity and high acceleration are the main reasons for the increase in $\mathrm{NO}_{\mathrm{x}}$ emission.

Figure 6 shows that the mass emission rate of $\mathrm{HC}$ first decreased and then increased with velocity in different acceleration ranges. However, at a fixed velocity, the HC emission slightly changed under different accelerations, consistent with the effect of acceleration on emission described in Section 2.2.

In the velocity range from 10 to $50 \mathrm{~km} / \mathrm{h}$, the mass emission rates of $\mathrm{HC}$ are relatively stable, mostly in the range of $0.06 \ldots 0.1 \mathrm{mg} / \mathrm{s}$. When the velocity ranged from 30 to $40 \mathrm{~km} / \mathrm{h}$ with more than $1.5 \mathrm{~m} / \mathrm{s}^{2}$ acceleration, the $\mathrm{HC}$ mass emission rate reached its peak of $0.18 \mathrm{mg} / \mathrm{s}$. This indicates that velocity is the major factor affecting $\mathrm{HC}$ emission, and incomplete combustion caused by high acceleration under medium velocity results in high emission.

Figure 7 shows that the mass emission rate of $\mathrm{CO}$ first increased and then decreased with the increase in velocity in different acceleration ranges. At a fixed velocity, the $\mathrm{CO}$ mass emission rate at a high acceleration above $1 \mathrm{~m} / \mathrm{s}^{2}$ is significantly higher than that at a low acceleration.

When the acceleration is less than $1 \mathrm{~m} / \mathrm{s}^{2}$, the CO mass emission rate slightly changed under different velocities and accelerations. However, the mass emission rate of $\mathrm{CO}$ was high when the acceleration was higher than $1 \mathrm{~m} / \mathrm{s}^{2}$ and the velocity ranged from 20 to $50 \mathrm{~km} / \mathrm{h}$. Thus, a high acceleration increases the amount of gas mixture.

In summary, the incomplete combustion in high acceleration and high combustion temperature inside the cylinder can be prevented when light-duty vehicles run at a moderate velocity from 30 to $50 \mathrm{~km} / \mathrm{h}$ and the acceleration is less than $0.5 \mathrm{~m} / \mathrm{s}^{2}$. Thus, the emission performance of light-duty vehicles can be improved.

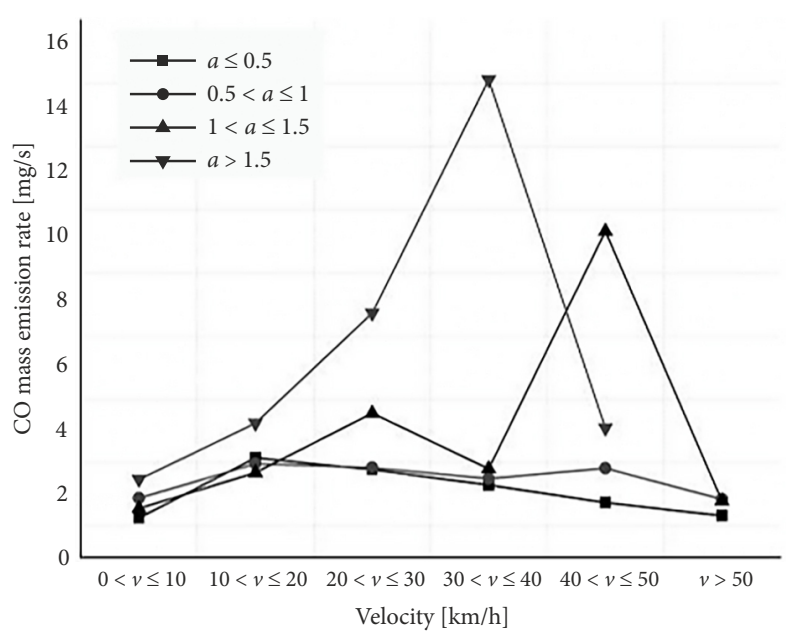

Figure 7. Effect of both velocity and acceleration on the mass emission rate of $\mathrm{CO}$ 


\section{Microscopic emission model}

Changes in velocity and acceleration would vary engine performance, thus affecting vehicle emissions. Thus, velocity and acceleration can be used to establish a microscopic emission prediction mode.

\subsection{Velocity regression model}

Single regression models of three emissions were established based on a single parameter of velocity, closely related to vehicle mass emission rates.

The modelling data selection process is shown in Figure 8. First, 13 groups of emission data were selected under a velocity of $0,5,10,15,20,25,30,35,40,45,50$, 55 and $60 \mathrm{~km} / \mathrm{h}$. Then, the average emission rates were calculated according to the corresponding velocity, and the average emission rates of $\mathrm{NO}_{\mathrm{x}}, \mathrm{HC}$, and $\mathrm{CO}$ with respect to velocity are shown in Figures 9-11. According to the calculation data, the model results can be obtained from Equations (1)-(3) through multiple regression using Origin Pro 9.0 software (https://www.originlab.com/origin):

$\mathrm{NO}_{\mathrm{x}}:$
$y_{\mathrm{NO}_{\mathrm{x}}}=3.20529 \cdot 10^{-4}+6.22451 \cdot 10^{-5} \cdot x ;$

$\mathrm{HC}$ :

$y_{\mathrm{HC}}=7.24546 \cdot 10^{-4}+6.73095 \cdot 10^{-5} \cdot x-$

$2.29452 \cdot 10^{-6} \cdot x^{2}+2.16185 \cdot 10^{-8} \cdot x^{3}$;

\section{$\mathrm{CO}:$}

$y_{\mathrm{CO}}=0.00868+0.0024 \cdot x-$

$9.92745 \cdot 10^{-5} \cdot x^{2}+9.62459 \cdot 10^{-7} \cdot x^{3}$,

where: $y$ is the instantaneous emission rate $[\mathrm{mg} / \mathrm{s}] ; x$ is the instantaneous velocity $[\mathrm{km} / \mathrm{h}], 0<x<60 \mathrm{~km} / \mathrm{h}$.

The above three regression equations are mathematical expressions of velocity-regression model and reflect the relationship between velocity and average mass emission rates. As this model is based on only one factor, it has a simple form, and the results can be easily predicted. This characteristic further facilitates it to coordinate with other models. However, because many factors affect vehicle emissions on actual roads and the effect of velocity only accounts for about $30 \%$, the single-factor velocity model has some limitations.

\subsection{Binary regression model}

The binary regression model predicts the emission rate based on both velocity and acceleration. In this model, the acceleration is selected from -5 to $5 \mathrm{~km} / \mathrm{h} / \mathrm{s}$, and the velocity is selected from 0 to $60 \mathrm{~km} / \mathrm{h}$. Each velocity has 11 points corresponding to acceleration $(-5,-4,-3,-2$, $-1,0,1,2,3,4,5)$.

The modelling process is as follows: First, set a group of regression models to express the relationship between instantaneous emission rate and velocity, and then divide the emission rates into 11 groups based on acceleration. Next, set Equation (4) for each group using the cubic re-

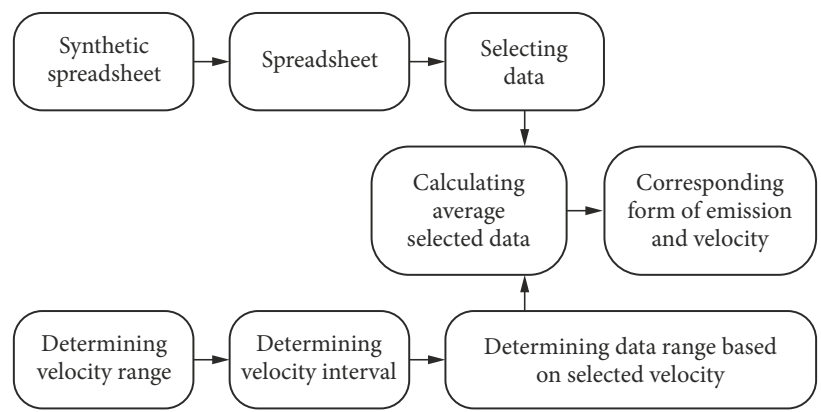

Figure 8. Processing procedure for selecting modelling data

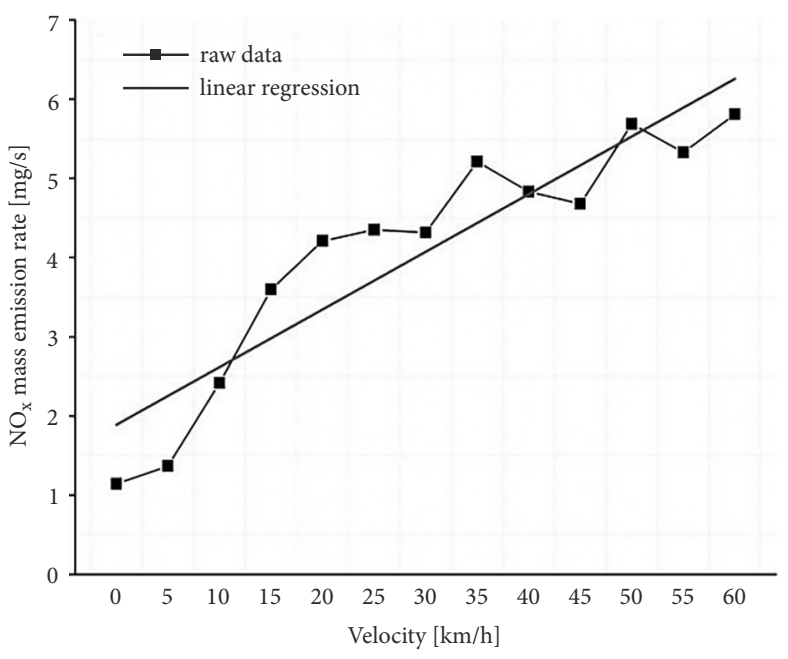

Figure 9. Velocity-emission rate regression curve of $\mathrm{NO}_{\mathrm{x}}$

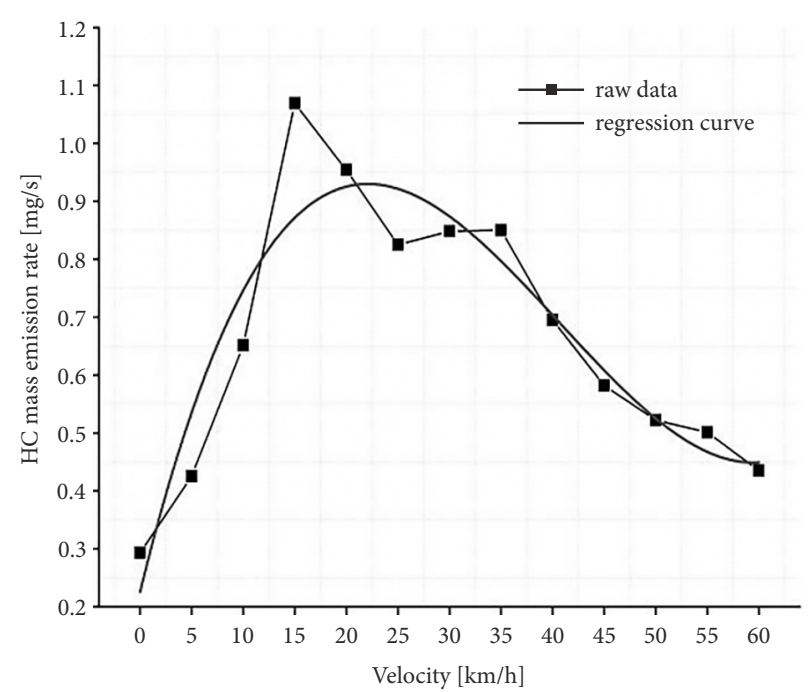

Figure 10. Velocity-emission rate regression curve of $\mathrm{HC}$

gression method. As a result, four groups of coefficients $a_{v}, b_{v}, c_{v}$, and $d_{v}$ can be obtained, and each group has 11 statistics related to the corresponding acceleration.

$$
E_{A}=a_{v}+b_{v} \cdot v+c_{v} \cdot v^{2}+d_{v} \cdot v^{3},
$$

where: $E_{A}$ is the instantaneous mass emission rate $[\mathrm{mg} / \mathrm{s}]$; $a_{v}, b_{v}, c_{v}$, and $d_{v}$ are the regression coefficients; $v$ is the instantaneous velocity $[\mathrm{km} / \mathrm{h}]$. 


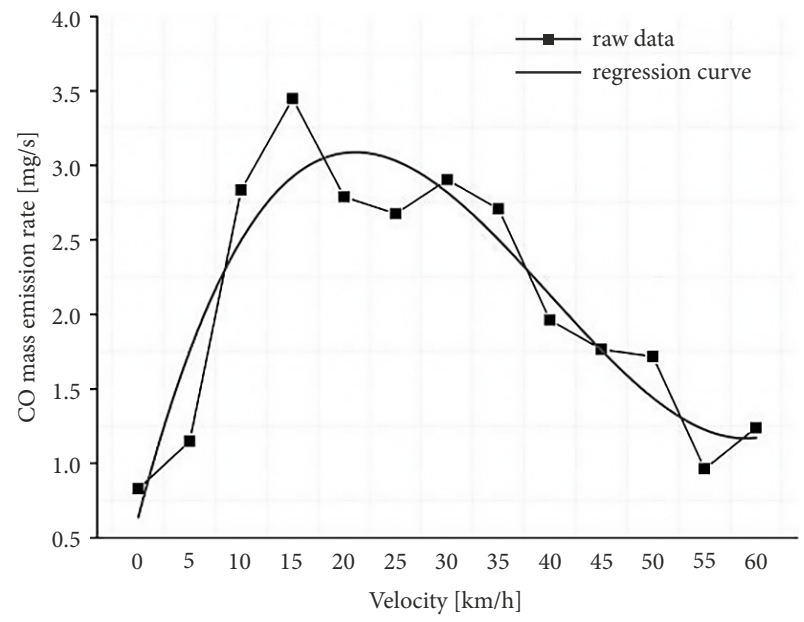

Figure 11. Velocity-emission rate regression curve of CO

The binary regression model of emission rate can be expressed as follows:

$$
\begin{aligned}
& E_{\mathrm{NO}_{\mathrm{x}}}=\sum_{i, j=0}^{3} a_{i j} \cdot a^{i} \cdot v^{j} ; \\
& E_{\mathrm{HC}}=\sum_{i, j=0}^{3} b_{i j} \cdot a^{i} \cdot v^{j} ; \\
& E_{\mathrm{CO}}=\sum_{i, j=0}^{3} c_{i j} \cdot a^{i} \cdot v^{j},
\end{aligned}
$$

where: $E_{\mathrm{NO}_{\mathrm{x}}}, E_{\mathrm{HC}}$, and $E_{\mathrm{CO}}$ are the mass emission rate of $\mathrm{NO}_{\mathrm{x}}, \mathrm{HC}$, and CO, respectively [mg/s]; $a_{i j}, b_{i j}$, and $c_{i j}$ are the model coefficients; $a^{i}$ is the acceleration $[\mathrm{km} / \mathrm{h} / \mathrm{s}]$, $-5<a<5 \mathrm{~km} / \mathrm{h} / \mathrm{s} ; v^{j}$ is the velocity $[\mathrm{km} / \mathrm{h}], 0<v<60 \mathrm{~km} / \mathrm{h}$.

Table 4 shows the model coefficients of binary regression.

The binary regression model has diverse applications. It can be used to predict instantaneous emission under a velocity of $0 \ldots 60 \mathrm{~km} / \mathrm{h}$ and acceleration of $-5 . .5 \mathrm{~km} / \mathrm{h} / \mathrm{s}$. Moreover, this model can be easily combined with other models to quantify emission.
Table 4. Binary regression model coefficients

\begin{tabular}{|c|c|c|c|}
\hline $\begin{array}{c}\text { Variable } \\
\text { parameters }\end{array}$ & $\mathrm{NO}_{\mathrm{x}}$ & $\mathrm{HC}$ & $\mathrm{CO}$ \\
\hline$a$ & -1.646013 & -0.480287 & 7.115069 \\
\hline$a^{2}$ & 0.257026 & 0.017818 & 7.299528 \\
\hline$a^{3}$ & 0.059187 & 0.074631 & 1.507933 \\
\hline$a \cdot v$ & 0.162353 & 0.070015 & -0.592252 \\
\hline$a^{2} \cdot v$ & -0.034504 & -0.003120 & -0.724626 \\
\hline$a^{3} \cdot v$ & -0.008106 & -0.010206 & -0.139018 \\
\hline$a \cdot v^{2}$ & -0.002891 & -0.002256 & 0.011174 \\
\hline$a^{2} \cdot v^{2}$ & 0.000896 & 0.0000678 & 0.013234 \\
\hline$a^{3} \cdot v^{2}$ & 0.000262 & 0.000341 & 0.002491 \\
\hline$a \cdot v^{3}$ & 0 & 0.0000208 & 0 \\
\hline$a^{2} \cdot v^{3}$ & 0 & 0 & 0 \\
\hline$a^{3} \cdot v^{3}$ & 0 & -0.00000315 & 0 \\
\hline$v$ & 0.361401 & 0.032044 & 1.403942 \\
\hline$v^{2}$ & -0.005651 & -0.000597 & -0.026676 \\
\hline$v^{3}$ & 0 & 0 & 0 \\
\hline Constant & -0.113739 & 0.412267 & 13.288111 \\
\hline
\end{tabular}

\subsection{Neural network model}

As the emission data nonlinearly vibrates with velocity and acceleration, a neural network model was established to ensure algorithmic accuracy and computational efficiency. The neural network toolbox of MATLAB (https:// www.mathworks.com/products/matlab.html) was used to analyse and program to perform the following calculation, as shown in Figure 12.

A Body Fat (BF) neural network model was established with two hidden layers. The tansing and logsig functions were used as the transfer functions of the emission rate model. The third layer function uses purelin linear transfer function. The relationship of BF mapping neural network model can be expressed as follows:

$$
E=f^{3}\left(W^{3} \cdot f^{2}\left(W^{2} \cdot f^{1}\left(W^{1} \cdot P+b^{1}\right)+b^{2}\right)\right)+b^{3},
$$

where: $E$ is the emission rate; $W^{1}, W^{2}$ and $W^{3}$ are the

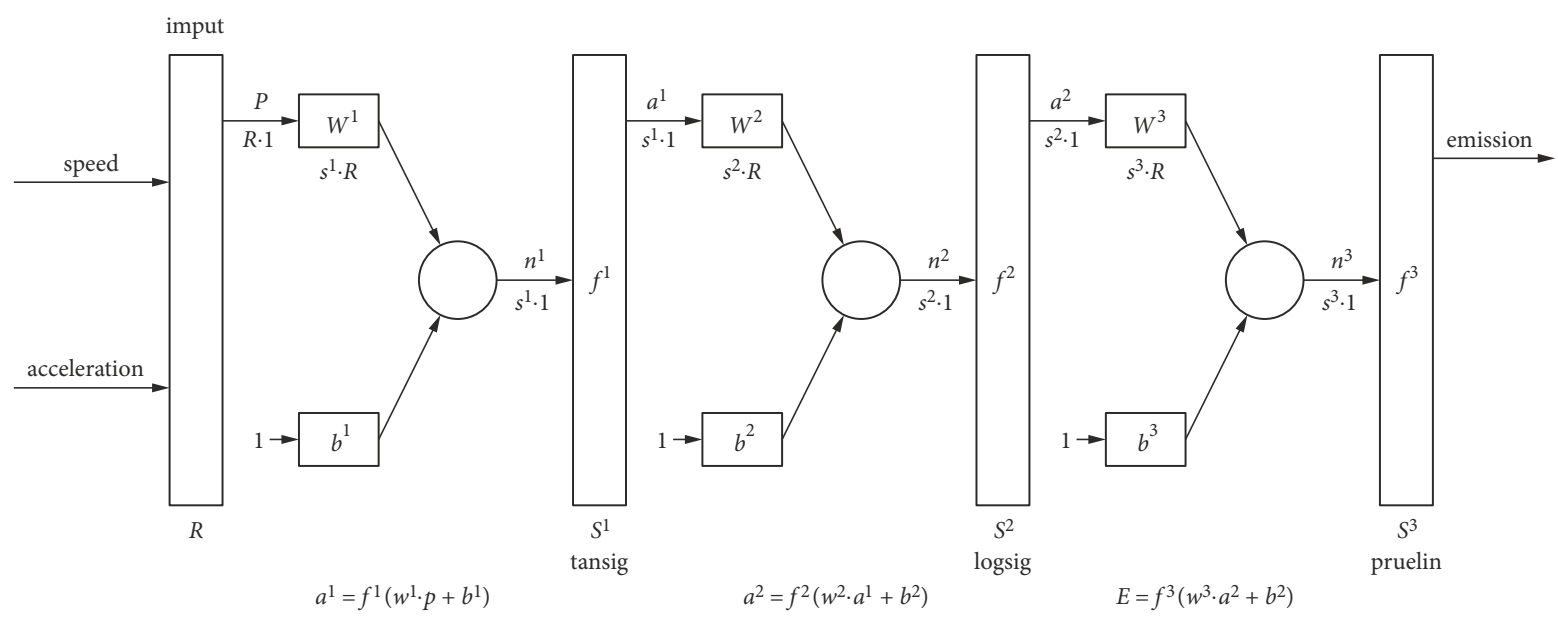

Figure 12. Structure of neural network model 
weights of neural network; $b^{1}, b^{2}$ and $b^{3}$ are the deviation matrices; $P$ is the input vector (velocity, acceleration); $f^{1}$ is the nonlinear transfer function (transig); $f^{2}$ is the nonlinear transfer function (logsig); $f^{3}$ is the linear transfer function (purelin).

In this model, 660 sets of data were selected from the emission test data under a velocity of $0 \ldots 60 \mathrm{~km} / \mathrm{h}$ and acceleration of $-4 \ldots 4 \mathrm{~m} / \mathrm{s}^{2}$. The input is instantaneous velocity and acceleration, and the output is instantaneous mass emission rates of $\mathrm{NO}_{\mathrm{x}}, \mathrm{HC}$, and $\mathrm{CO}$. The neural network model parameters are shown in Table 5.

\subsection{Comparative analysis of models}

The predicted accuracy under different emission models, total error, second-based error, related coefficient, and sum of squared error as the evaluation indexes were compared to validate different models.

The total error can be expressed as follows:

$$
\text { total error }[\%]=\frac{\operatorname{abs}(X-Y)}{Y} \cdot 100 \% \text {, }
$$

where: $X$ is the sum of predicted value; $Y$ is the sum of raw value.

The second-based error can be expressed as follows:

$$
\text { second based error }[\%]=\frac{\operatorname{abs}(x-y)}{y} \cdot 100 \% \text {, }
$$

where: $x$ is the per second predicted value; $y$ is the per second raw value.
Table 5. Parameters of neural network model

\begin{tabular}{|c|c|c|c|}
\hline Model & $\mathrm{NO}_{\mathrm{x}}$ & $\mathrm{HC}$ & $\mathrm{CO}$ \\
\hline $\begin{array}{c}\text { Number of } \\
\text { first hidden } \\
\text { layer nodes }\end{array}$ & 30 & 25 & 30 \\
\hline $\begin{array}{c}\text { Number } \\
\text { of second } \\
\text { hidden layer } \\
\text { nodes }\end{array}$ & 15 & 10 & 15 \\
\hline $\begin{array}{c}\text { Training } \\
\text { times }\end{array}$ & 2081 & 1950 & 4920 \\
\hline $\begin{array}{c}\text { Network } \\
\text { error }\end{array}$ & 0.1 & 0.1 & 0.1 \\
\hline Input & $\begin{array}{c}\text { velocity; } \\
\text { acceleration }\end{array}$ & $\begin{array}{c}\text { velocity; } \\
\text { acceleration }\end{array}$ & $\begin{array}{c}\text { velocity; } \\
\text { acceleration }\end{array}$ \\
\hline Output & $\begin{array}{c}\text { NO } \\
\text { instantaneous } \\
\text { mass emission } \\
\text { rate }\end{array}$ & $\begin{array}{c}\text { HC } \\
\text { instantaneous } \\
\text { mass emission } \\
\text { rate }\end{array}$ & $\begin{array}{c}\text { CO } \\
\text { instantaneous } \\
\text { mass emission } \\
\text { rate }\end{array}$ \\
\hline
\end{tabular}

The related coefficient can be expressed as follows:

$$
\rho_{x y}=\frac{\operatorname{cov}(X, Y)}{\sigma_{x} \cdot \sigma_{y}},-1 \leq \rho_{x y} \leq 1,
$$

where: $\sigma_{x}$ is the standard deviation of predicted value; $\sigma_{y}$ is the standard deviation of raw value,

$$
\operatorname{cov}(X, Y)=\frac{1}{n} \cdot \sum_{i=1}^{n}\left(x_{i}-\mu_{x}\right) \cdot\left(y_{i}-\mu_{y}\right),
$$

Table 6. $\mathrm{NO}_{\mathrm{x}}$ emission model error analysis

\begin{tabular}{|l|c|c|c|}
\hline Parameters & Vodel & Binary regression model & Neural network model \\
\hline Total error & $2.65 \%$ & $7.32 \%$ & $3.26 \%$ \\
\hline Second-based error & $24.90 \%$ & $56.84 \%$ & $18.77 \%$ \\
\hline Related coefficient & 0.85554 & 0.692776 & 0.99202 \\
\hline Total variance & 0.00052 & - & $2.5430 \cdot 10^{-4}$ \\
\hline Number of coefficients & 2 & 12 & - \\
\hline
\end{tabular}

Table 7. HC emission model error analysis

\begin{tabular}{|l|c|c|c|}
\hline Parameters & Vodel & Binary regression model & Neural network model \\
\hline Total error & $10.70 \%$ & $16.37 \%$ & $2.80 \%$ \\
\hline Second-based error & $30.14 \%$ & $54.70 \%$ & $31.57 \%$ \\
\hline Related coefficient & 0.82914 & 0.41047 & 0.98462 \\
\hline Total variance & $8.50 \cdot 10^{-5}$ & - & $1.57 \cdot 10^{-5}$ \\
\hline Number of coefficients & 4 & 14 & - \\
\hline
\end{tabular}

Table 8. CO emission model error analysis

\begin{tabular}{|l|c|c|c|}
\hline Parameters & Model & Binary regression model & Neural network model \\
\hline Total error & $10.28 \%$ & $11.04 \%$ & $1.43 \%$ \\
\hline Second-based error & $31.52 \%$ & $44.56 \%$ & $15.14 \%$ \\
\hline Related coefficient & 0.90857 & 0.64916 & 0.98612 \\
\hline Total variance & 0.00345 & - & 0.018405 \\
\hline Number of coefficients & - & 12 & - \\
\hline
\end{tabular}


where: $x_{i}$ is the predicted emission rate; $y_{i}$ is the raw emission rate; $\mu_{x}$ is the average of predicted value; $\mu_{y}$ is the average of raw value.

The total variance can be expressed as follows:

$$
\text { total variance }=\sum\left(x_{i}-y_{i}\right)^{2} \text {. }
$$

Tables 6-8 show that the total error of vehicle emission prediction in the three models is less than $17 \%$, and the second-based error is less than $30 \%$. The related coefficients of velocity regression model and neural network model are above 0.8 . This shows that the established emission models can be used to make relatively accurate prediction of vehicle emission on actual roads. The velocity regression model has a relatively simple parameter. The prediction accuracy of $\mathrm{CO}$ emission was higher than that of other two models. Full combustion occurred in the absence of high CO emissions. Therefore, the model is suitable for vehicle in cold start. The oxygen concentration on automobile emission area reaches a plateau; acceleration and idle state can be predicted. It can be applied to combine with traffic simulation models to evaluate and analyse microscopic emission on urban road network and intersection. The binary regression model has good generality. However, the error per second is larger, and the correlation is lower than the other two models. It is suitable to estimate the micro emission of light-duty vehicles in urban roads. The neural network model has the highest correlation in the three models, and its prediction results are most accurate. It is suitable for the good prediction accuracy of light-duty vehicle emission based on actual road conditions, and it can be applied to the accurate prediction of urban road intersection and small area road network. However, its coefficient matrix is complex, which is not conducive to traffic simulation model integration.

\section{Conclusions}

First, light-duty vehicles on urban road were selected as the study object. An on-road emission test platform was established, and actual road experiments were conducted. The mass emission rates of three emissions and the corresponding driving conditions were obtained. Then, the effect of velocity, acceleration, and the joint distribution of both on vehicle emission was evaluated. Velocity regression model, binary regression model and neural network model were established by regression and neural network, accurately reflecting the instantaneous emission rates of light-duty vehicles on actual roads:

1) with the increase in velocity, the mass emission rate of $\mathrm{NO}_{\mathrm{x}}$ gradually increases, and the mass emission rates of $\mathrm{HC}$ and $\mathrm{CO}$ first increase and then decrease. With the increase in acceleration, the mass emission rates of three pollutants increase and decrease erratically, but generally show an increasing trend;

2) considering both velocity and acceleration, emission is the minimum under a moderate velocity of $30 \ldots 50 \mathrm{~km} / \mathrm{h}$ and an acceleration of less than $0.5 \mathrm{~m} / \mathrm{s}^{2}$
3) the velocity regression model can be coordinated with other traffic models, but its application is limited for only one parameter. Both the binary regression model and neural network model have extensive applications, but the binary regression model has poor accuracy. Although the neural network model has more accurate prediction, it cannot be integrated with other models because of its complex coefficient matrix.

In conclusions, the three emission models developed in the present work provides quantification predictive tools of light-duty vehicle emissions of dynamic road network. This information is essential for analysis on current situation of light-duty vehicle emissions, at the same time; it is the basic work of making emission control strategy. Future research will be focused on more vehicle types such as natural gas vehicles and hybrid vehicles, the effects of road grade and slope on emissions will be also taken into account. Furthermore, Electric Vehicles (EVs) are rapidly developing in the Chinese market due to their zero emission and high efficiency. At present, EVs holdings maintain a growth rate of more than $25 \%$ per year. Our followup study will combine the changes in vehicle composition of different energy types brought about by the increase in EVs holdings to further analyse the reduction in vehicle emissions due to EVs growth.

\section{Acknowledgements}

This work was supported by the National Natural Science Foundation of China (Grants No 51508315 and 51608313), the technological Development Project of Shandong Province (Grant No 2016GGB01539) and the Natural Science Foundation of Shandong province of China (Grant No ZR2015EL046).

\section{Contribution}

Dong Guo and Feng Sun conceived and designed the study.

Dong Guo completed model analysis.

Dong Guo and Feng Sun wrote the paper.

Dong Guo, Jinbao Zhao, Yi Xu, Feng Sun, Kai Li, Juan Wang, Yuhang Sun performed the experiments; reviewed, edited and approved the paper.

\section{Disclosure statement}

This article do not have any competing financial, professional, or personal interests from other parties.

\section{References}

Bai, S.; Eisinger, D.; Niemeier, D. 2009. MOVES versus EMFAC: comparison of greenhouse gas emissions using Los Angeles County, in TRB 88th Annual Meeting Compendium of Papers DVD, 11-15 January 2009, Washington, DC, US, 1-18. 
Boulter, P. G.; McCrae, I. S.; Barlow, T. J. 2007. A Review of Instantaneous Emission Models for Road Vehicles. Published Project Report 267. Transport Research Laboratory, Wokingham, UK. 64 p. Available from Internet:

https://trl.co.uk/reports/PPR267

Cheng, Z.; Xue, Z.; Zhang, Z.; Xu, Y.; Li, C.; Yi, P. 2009. Study on the establishment of vehicle emission inventories, Environmental Pollution and Control (9): 76-81. (in Chinese).

Davis, N.; Lents, J.; Osses, M.; Nikkila, N.; Barth, M. 2005. Development and application of an international vehicle emissions model, Transportation Research Record: Journal of the Transportation Research Board 1939: 156-165. https://doi.org/10.1177/0361198105193900118

Demir, E.; Bektaş, T.; Laporte, G. 2011. A comparative analysis of several vehicle emission models for road freight transportation, Transportation Research Part D: Transport and Environment 16(5): 347-357. https://doi.org/10.1016/j.trd.2011.01.011

EPA. 2007. Motor Vehicle Emission Simulator Highway Vehicle Implementation (MOVES-HVI) Demonstration Version: Software Design and Reference Manual: Draft. 2007. US Environmental Protection Agency (EPA). 232 p.

Iqbal, A.; Allan, A.; Zito, R. 2016. Meso-scale on-road vehicle emission inventory approach: a study on Dhaka City of Bangladesh supporting the 'cause-effect' analysis of the transport system, Environmental Monitoring and Assessment 188(3): 149. https://doi.org/10.1007/s10661-016-5151-4

Gao, Y; Yu, L.; Song, G.; Zuo, Y.; Hao, Y. 2012. Quantitative modeling and simulation of traffic emissions, Journal of System Simulation (4): 887-891. (in Chinese).

Guo, D.; Gao, S.; Zou, G.-D.; Tan, D.-R.; Wang, X.-Y.; Shao, J.-J. 2012. Quantitative evaluation method of vehicle emission in urban region, Journal of Traffic and Transportation Engineering 12(1): 72-78. (in Chinese).

Guo, D.; Sun, F.; Zhao, J. 2017. Method for Estimation of Urban Area Vehicle Emission and Reduction Strategy Analysis. China Communications Press. 186 p. (in Chinese).

Guo, D.; Zhang, H.; Zheng, C.; Gao, S.; Wang, D. 2016. Analysis of the future development of Chinese auto energy saving and environmental benefits, Systems Engineering - Theory \& Practice (6): 1593-1599. (in Chinese).

Kouridis, C.; Ntziachristos, L.; Samaras, Z. 2000. COPERT III: Computer Programme to Calculate Emissions from Road Transport: User Manual (Version 2.1). European Environment Agency (EEA), Copenhagen, Denmark. 46 p. Available from Internet: https://www.eea.europa.eu/publications/Technical_report_No_50

Li, J.; Zhang, J.-H. 2014. Vehicle routing problem with time windows based on carbon emissions and speed optimization, Systems Engineering - Theory \& Practice (12): 3063-3072. (in Chinese).

Li, M.; Xu, J.; Dai, C. 2009. The features of emissions control technology of light-duty gasoline vehicles in different regulation stages, Automotive Engineering (8): 741-745. (in Chinese).

Li, X.-X.; Sun, G.-J.; Tian, W.-L.; Zhang, Q.-Y. 2012. Study on abatement policy of $\mathrm{NO}_{\mathrm{x}}$ emission from vehicles in Hangzhou during 12th five-year plan, China Environmental Science (8): 1416-1421. (in Chinese).

Liu, J.; Dong, J.-J.; Shi, X.-P.; Wang, H.-Z.; Yang, H.-M. 2011. Research for $\mathrm{NO}_{\mathrm{x}}$ emission of Nanjing vehicle based on IVE Model, Applied Mechanics and Materials 99-100: 1341-1345. https://doi.org/10.4028/www.scientific.net/AMM.99-100.1341
Qiu, F.; Zhang, C.; Huang, D.; Du, W.; Wang, M.; Hu, Z. 2015. Characteristics of $\mathrm{HC}$ emission from dual-fuel engine under transient operating conditions, Chinese Journal of Environmental Engineering (1): 312-316. (in Chinese).

Tang, W.; Yang, Q.; Huang, C.; Lu, B.; Xia, Y.; Jing, B.; Lu, Q.; Lu, J. 2018. Study on characteristics of pollutant emission from motor vehicles in Hangzhou based on large data analysis and IVE model, Acta Scientiae Circumstantiae (1): 71-78. (in Chinese).

Zheng, F.; Li, J.; Van Zuylen, H.; Lu, C. 2017. Influence of driver characteristics on emissions and fuel consumption, Transportation Research Procedia 27: 624-631.

https://doi.org/10.1016/j.trpro.2017.12.142

Zi, K.; Huang, Y.; Tu, X.; Yang, R. 2006. An investigation into the total amount of pollutants emission from motor vehicle in city, Automotive Engineering (8): 707-710. (in Chinese). 